\title{
Personality and Meaning in Life: The Mediating Role of Wellness
}

\author{
Nur Demirbaş-Çelik ${ }^{1, *}$, Fidan Korkut-Owen² \\ ${ }^{1}$ Education Faculty, Alanya Alaaddin Keykubat University, Turkey \\ ${ }^{2}$ Education Faculty, Bahçeşehir University, Beşiktaş, Turkey
}

Copyright $\bigcirc 2018$ by authors, all rights reserved. Authors agree that this article remains permanently open access under the terms of the Creative Commons Attribution License 4.0 International License

\begin{abstract}
Big two is based on the personality traits of Stability and Plasticity, also known as a new construct named the Big Two, which is itself based on the Big Five. The purpose of this study was to examine the mediating role of wellness in the relationship between the Stability and Plasticity and meaning in life. The research had 273 adult participants; 189 of whom were female and 84 were male, all within the age range of 22 and $44(\bar{x}=30.08$; $\mathrm{SD}=5.39$ ). The Big Five Inventory, The Well-Star Scale-Adult Form, Meaning in Life Questionnaire and a Brief Personal Information Form were used for data collection. Data analysis was done by structural equation modeling and bootstrap procedure. Results show that wellness fully mediated the relationship between plasticity and meaning in life.
\end{abstract}

Keywords Big Two, Personality, Meaning in Life, Wellness

\section{Introduction}

The link between individuals' personality traits and finding meaning in their lives is an issue that attracts the attention of researchers. There are some researches [1,2] showed that personality traits related to meaning in life. In recent years, it is seen that the amount of research on personality traits and meaning research has increased; and concepts such as perceived illness or perceived wellness have been examined within this context [3]. In an extensive research conducted with both individuals diagnosed with a disease and healthy individuals, it was found that high level of meaning in life is directly linked to having better health [4]. The concept of wellness is approached as a healthy lifestyle in literature [5]. Examining healthy lifestyle studies [6,7] the question of what the mediating role of wellness is in regard to healthy lifestyles within the link between personality traits and meaning in life comes to mind. To answer this question, this study summarizes the research on the connections between theoretical explanations and concepts pertaining to personality, meaning in life and wellness.

\subsection{The Big Two}

The theory of the Big Five argues that individuals have a series of traits that affect their emotional, thought and behavior patterns and indicates these characteristics can be grouped into five basic traits [8]. Digman [9] asserted that these five traits can be grouped under two series of high-level traits. He conceptualized this structure of super-traits or meta-traits, called The Big Two. These super-traits defined as "factor alpha $(\alpha)$ " and "factor beta $(\beta)$ ". Factor $(\alpha)$ comprises of agreeableness, conscientiousness and low-level neuroticism; whereas factor $(\beta)$ consists of extraversion and openness. DeYoung et al. [10] named the meta-traits which Digman [9] called factor $(\alpha)$ and factor $(\beta)$, stability and plasticity, respectively. According to the big two, low-level neuroticism, agreeableness and conscientiousness traits reflect the stability in social and motivational domains. Extraversion and openness to experience traits represent the plasticity in behavioral and cognitive domains. These traits were named Morality/Social Propriety and Dynamism by Saucier et al. [11] in their study on Greek culture; and Zhou et al. [12] argued that this construct is valid among Chinese culture as well. As a result, the confirmation of super-traits in different cultures including Turkey [13] with different tools demonstrates that this structure is a valid model.

When discussing the factors involving stability, conscientiousness is essential to maintain social interaction and long and short-term objectives. On the other hand, low level neuroticism is an important indicator of stability. The traits of agreeableness and conscientiousness prevent impulsive behavior. This is also a factor that reduces the spontaneity [14] Therefore, the close link between stability and the control mechanism is emphasized $[10,15]$. For example, it is easier for children 
with a stable personality trait to socialize [14]. Stability refers to the degree to which an individual has personal control and is socially compatible. Plasticity, contrary to stability, correlates negatively to agreeableness. In other words, individuals who has plasticity trait do not tend to be socially compatible [16]. Plasticity includes cognitive exploration/research. This tendency to explore involves creating new objectives, interpretations and strategies [17] Moreover, there are studies that show that the super-traits of stability and plasticity could be hereditary $[10,16,18]$. Additionally, it was asserted that stability could be based on ego control in psychoanalytic theory, and the term socialization in behavioral theory; and that plasticity could be based on the concepts of self-actualization and personal growth in humanistic approach $[15,16]$. Digman [9] stated that the factors that involve stability are related to social desirability and that these factors are acquired through means such as impulse control and defense mechanisms, depending upon development. Moreover, even though stability and plasticity appear to be opposing structures, they are closely related to each other [14].

\subsection{Personality and Meaning in Life}

There have been many different definitions proposed for meaning in life because of the difficulty of describing it. One of these defines meaning in life as to the degree to which an individual has an objective, a mission, or a comprehensive life goal that makes one's life meaningful [19] and meaning in life is addressed as a cognitive structure that questions what one's meaning of life contributes to [20]. Another definition evaluates meaning in life as a representation of events, relations, objects in one's mind [21]. By examining the commonalities among different definitions, it can be said that meaning in life consists of three elements. These are comprehension, purpose and individual's perception of life as worth living [22]. Upon review, it can be seen that purpose and meaning are used interchangeably at times in these studies e.g. Seligman and Csikszentmihalyi [23]. However, goals and objectives could be mostly explained via motivational theories, whereas meaning in life could be comprehensively explained as being in harmony in respect to the world, themselves, the relationship between themselves and the world, and therefore there is also research that suggests that these are discrete structures [24]. In a study conducted with university students in Turkey, it was concluded that meaning in life and purpose are related [26]. The studies about the relationship between meaning in life and wellbeing were examined e.g: $[26,27,29]$.

Meaning in life is positively associated with the traits of extraversion, agreeableness and conscientiousness, but it is negatively associated with neuroticism $[1,30]$. In German culture, the five traits relating to personality are associated with meaning in life [31]. In another study, it was found that the strongest explanatory personality trait for meaning in life is neuroticism; while the least explanatory personality trait for meaning in life is extraversion [32]. Terzi and Üzbe [33] conducted a study with individuals between the ages of 18-65; and they found that the presence of meaning in life correlates with all personality traits, and that the characteristics of openness and neuroticism explain the meaning in life. Lavigne et al. [34] found that personality factors correlate with meaning in life, but that this situation is not valid for each factor. For instance, participants who have the trait of openness at a high level tend to provide their meaning sources from questioning, learning and challenging traditions; whereas individuals with the trait of conscientiousness and extraversion at a high-level tend to see achievements in work, health and family life as their source of meaning. In the study, responsibility and questioning/learning were discussed as components of meaning and these two components were identified with stability and plasticity, respectively.

\subsection{Meaning in Life and Wellness}

Studies appear to be supportive in regard to the relationship between personality and meaning in life. Study results in recent years have led to research that may affect the behaviour of individuals in this regard; seeing as healthy lifestyles prevent many diseases. The concept of wellness which is approached as a healthy lifestyle, which in the literature had previously only been attempted to be described, has been used in the development of tactics regarding individuals' healthy living and the implementation of some health programs [35]. Corbin et al. [36] express that healthy lifestyles affect health and wellness by drawing attention to the fact that healthy lifestyles reduce the risk of contracting certain diseases and enhance wellness. Although the concept of wellness in regard to healthy lifestyles has a number of definitions, one of the most common descriptions was defined by Myers et al. [37]. According to them, wellness is being oriented towards maintaining one's health at an optimal level, integrating the body with the mind and soul, having personal objectives, and aiming to live a more meaningful life that is functional in all social, personal and ecological aspects. Upon reviewing different definitions in the literature, Miller and Foster [38] determined that wellness was approached as a choice, a process and a lifestyle. Additionally, according to definitions, they found that wellness was a holistic structure despite being multi-dimensional, and that it displayed features of pertaining to balance, being subjective and relative, and reflected the characteristics of healthy people. The most widely used model in a series of models developed to explain wellness is The Indivisible Self: An Evidence-based Model of Wellness [39]. Korkut-Owen and Owen [40] have developed a five-factor model utilizing the star metaphor, named The Well-Star Model that benefits from factors underlined in most models in 
the literature. These five factors were named emotional, spiritual, cognitive, social and physical factors, respectively [40].

In the literature, there are many studies on the relationship between meaning in life and wellness. According to Ryff [41] meaning in life is accepted as an indicator of wellness. The relationship between meaning in life and wellness was examined in numerous studies and a positive correlation was found between them $[1,43,44,45]$. According to Steger [20] the concept of meaning in life facilitates individuals' wellness. A positive correlation between the meaning in life and positive psychology components such as well-being, life satisfaction, and resilience has been proven by numerous studies $[44,45,46]$. Furthermore, the meaning in life is also closely linked to self-recovery power, ego resilience, and coping periods $[44,47,48]$. In recent years, there has been an increase in efforts to examine the variables that may have possible contributions to meaning in life [49]. There is evidence that positive affect is beginning with the idea that personality traits may be closely associated with meaning in life $(22,33,50]$. Weinstein [51] described well-being and meaning in life as closely associated with each other and these terms were considered to be interchangeable in most cases.

It was asserted that having a meaning in life is related to the wellbeing of people [20] Weinstein [51,52] expressed that meaning in life is the best way to understand the indicators of wellness. All models developed in order to explain wellness, which is one of the concepts in positive psychology, also allow for a spiritual dimension in regard to the meaning of life. This can be evaluated as an indicator of the presence of the relationship between wellness and meaning in life. In a study conducted with patients of life-threatening, chronic diseases, it was found that meaning in life is closely associated with physical and mental health [53]. In a study conducted with elders, it was found that meaning in life has a key role in suicide [54]. In a research examining the relationship between health and meaning in 66 studies, it was concluded that meaning in life may have a potential role in explaining physical health [24]. The wellness program prepared for graduate school students and teachers in the field of psychological counseling was found to be effective for their understanding of meaning in life [55]. This result is important in regard to it showing the link between wellness and meaning in life.

\subsection{Personality and Wellness}

Britzman and Henkin [56] state that understanding personality priorities that pertain to wellness tendencies through the wellness of individuals is important for increasing their wellness. In this sense, in the literature, several studies have shown that there is a relationship between personality traits and wellness and well-being. In a study conducted in middle-aged adults, the relationship between the five factors of the Big Five Theory and psychological well-being, which is closely related to wellness, were examined [57]. In the study, it was determined that self-acceptance, meaning of life and environmental dominance dimensions are associated with the personality dimensions of extraversion, neuroticism and conscientiousness; personal growth is related to openness to experience and extraversion; having good relationships with others is related to the extraversion and agreeableness, and lastly, autonomy is associated with neuroticism. In a study, Conway et al. [58] found that extraversion, agreeableness and conscientiousness are important for the prediction of healthy behaviors (wellness). Another study conducted by Marzuki and Ishak [59] suggests that wellness has a positive relationship with conscientiousness but is inversely related to agreeableness. Beginning with the idea that personality traits may be a possible predictor of health-related behavior patterns, in other words, a healthy lifestyle, a study which examined the relationship between five personality traits and four main healthy behaviors indicated that four traits excluding openness predict healthy behaviors. The results show that the personality is a reliable predictor of healthy lifestyle patterns [60]. Another research states that personality explains one third of wellness [61]. Therefore, the research shows that there is a relationship between personality and wellness. Because wellness has been defined as a new paradigm in health care [62], the role of personality as a reliable predictor of healthy lifestyle patterns needs to be investigated further.

\subsection{The Present Study}

The studies described above seem to suggest that some personality variables may be closely associated with both meaning in life and wellness. As the number of studies on meaning of life increase, we understand that meaning in life is an important indicator of well-being and health [49].

The studies on meaning in life show that elements such as well-being and health have the potential to explain meaning in life. One such investigation conducted by [55] demonstrated that participants' anxiety and meaning of life estimates were influenced by a structured wellness course. Previous literature which sought to investigate the relationship between wellness and meaning in life suggested that meaning in life is an indicator of wellness [41] and that meaning in life is rooted in wellness [63]. Myers and Sweeney's wellness model which is named the Indivisible Self-Model [39] proposes that there is higher-order wellness factor and five second-order factors. One of the second-order factors is Essential Self which is comprised of four components with one of them is being Spirituality. As a result, it can be said that meaning in life 
or Spirituality may have its origin in the overall factor of wellness. Since the dimensions of personality do not change or show very small changes after the age of around 30 [64] this would suggest that personality becoming more stable with age. On the other hand wellness is a dynamic process characterized by change (39) therefore wellness can be conceived to have a role between personality and meaning in life. The following model depicts the role of wellness as a mediator between the personality and the ability to find meaning in life.

The proposed model pertaining to the relationship between these concepts is presented in Figure 1. Thus, the following hypotheses were examined:

H1. The relationship between stability and meaning in life is mediated by wellness

H2. The relationship between plasticity and meaning in life is mediated by wellness

This proposed model seeks to investigate each of the Big Two factors and it influence on the meaning in life. The reason for this, as stated above, is the differentiation of the personality factors that explain meaning in life. Within this context, the aim of this study is to examine the mediating role of wellness in the relationship between personality factors and meaning in life in view of the Big Two Theory.

\section{Method}

\subsection{Participants}

A total of 273 adults comprised of 189 females (69.2\%) and $84(30.8 \%)$ males participated in the study. The ages of the participants ranged between 22 and $44(\overline{\mathrm{x}}=30.08$;
$\mathrm{SD}=5.39$ ). The participants were selected through convenience sampling from among adults who are taking a training certificate at a mid-sized university in the south of Turkey. All participants held a bachelor's degree and all had been taking classes to be a teacher. Slightly more than half $(156,57.1)$ were employed.

\subsection{Measures}

The data were collected using The Well-Star Scale-Adult Form, The Big Five Inventory, Meaning in Life Questionnaire, and a personal information form. Some brief information about the scales can be found below. A short personal form was prepared and used to identify the gender, age and occupation status of the participants. This form was given top of the scale kit.

\subsubsection{The Big Five Inventory (BFI)}

Based on the Big Five Personality traits theory, the Big Five Inventory was developed by John and Srivastava [65]. The scale consists of a total of 44 items, with five sub dimensions defined as "extraversion", "agreeableness", "conscientiousness", "neuroticism" and "openness". The BFI was rated on a five Likert scale and getting high scores from each subscale indicate that the related personality trait is exhibited at a high-level. The adaptation study of BFI to Turkish culture among university students was conducted by Sümer et al. [66]. In present study, the reliability coefficients are between .60 and .70. In this study, conscientiousness, agreeableness and neuroticism traits measure the stability scores, whereas extraversion and openness traits measure the plasticity.

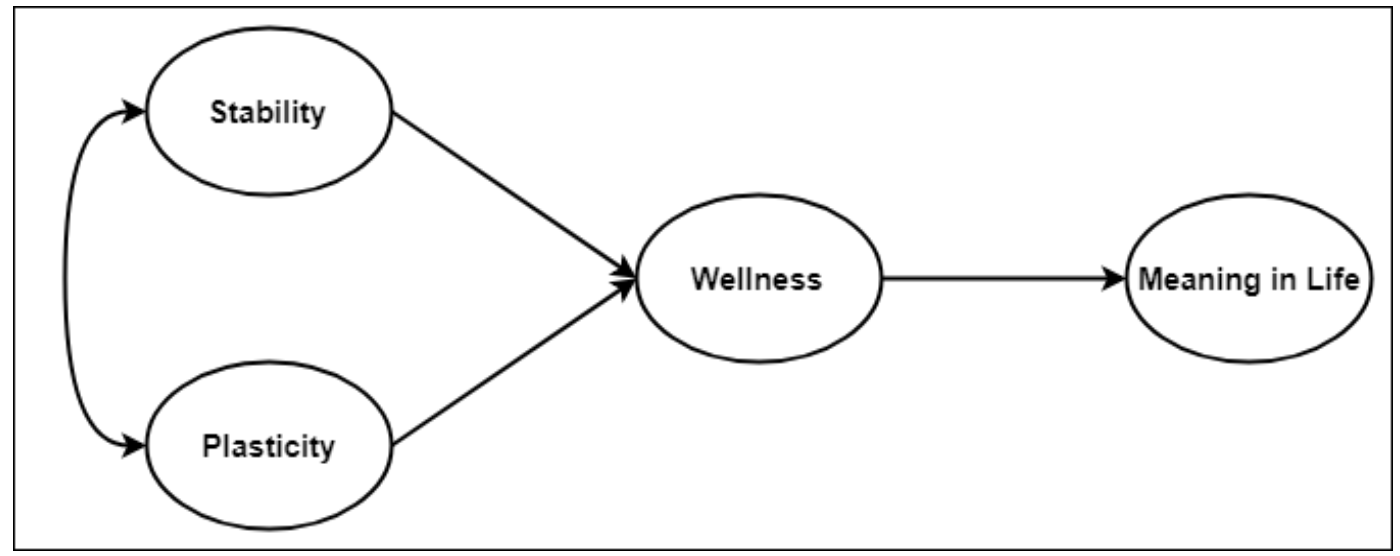

Figure 1. Proposed mediation model 


\subsubsection{The Well-Star Scale-Adult Form (WSS-AF)}

It was developed by Korkut-Owen, et al. [41] with university students at first. The scale is comprised of a total of 24 items and displays a five-dimensional structure. Sub dimensions of the scale can be scored separately. The internal consistency coefficient for the total of the scale is $\mathrm{r}=.85(\mathrm{p}<.01)$. Coefficients gathered from subscales are $.79 ; .77 ; .63 ; 0.57$ and .71 , respectively. To determine whether The WSS is also a valid and reliable tool for adults, a confirmatory factor analysis was performed by using the data gathered from 314 adult participants [64]. According to this, evidence that the adaptive values of the scale $\left[\chi^{2}\right.$ $(242, \mathrm{~N}=314)=280.11, \mathrm{p}<0.05 ; \mathrm{CFI}=0.95 ; \mathrm{IFI}=0.95$; $\mathrm{GFI}=0.93$; SRMR $=0.051$; RMSEA $=0.022]$ are also valid for adults was obtained. It was found that the internal consistency coefficient of WSS-AF is 0.73 ; whereas the reliability of the subscales changes between .75 and .80 . For this study, the Cronbach Alpha was determined to be .80 .

\subsubsection{The Meaning in Life Questionnaire}

MLQ, developed by Steger et al. [1] is a scale with 10 items and two dimensions defined as the presence of and the search for meaning in life. Five of these items measure the presence of meaning in life, and the other five measures the search for meaning in life. The MLQ scale was rated on a 7-point Likert scale. Because the dimensions of MLQ are independent from each other, a single dimension can be used in studies also e.g; [49]. In this research, the presence of meaning in life dimension, which aims to determine the level of individual's meaning of life, was utilized. In an adaptation study conducted among university students in Turkey, the internal consistency coefficient of this dimension was found to be .88 [68]. The internal consistency of the presence of meaning in life dimension in adult group was determined as .75 [69]. For this study, the reliability coefficient of the presence of meaning in life dimension was calculated to be .70 .

\subsection{Data Analysis}

Structural equation modelling (SEM) was used to evaluate the hypothesized mediation model. Data analysis was conducted in two steps: first the measurement model was tested then the structural model [70]. The measurement model refers to the relations of latent variables with their respective indicators. The indicators, in the model were defined according factor structures of the latent variables. The measurement model included four latent constructs with fifteen indicators. Extraversion and openness to experience were indicators for plasticity; neuroticism, conscientiousness, and agreeableness were indicators for stability. Emotional, spiritual, cognitive, social and physical factors were the BPNS. Presence were each represented by five items. Also, Anderson and Gerbing [70] and Weston and Gore [71] suggested to determine the best fitting model, by alternative nested models. The current study alternative structural and nested models were tested, and chi-square differences were determined. Finally, to evaluate mediation, confidence intervals of these indirect effects were calculated using the bootstrap procedure with 5000 samples [72].

\section{Results}

\subsection{Descriptive Statistics}

Descriptive statistics for all variables are provided in Table 1. Also, stability is significantly correlated with meaning in life $(r=0.14 ; \mathrm{p}<0.05)$, and with wellness $(\mathrm{r}=$ $0.18 ; \mathrm{p}<0.01)$; plasticity with meaning in life $(\mathrm{r}=0.30 ; \mathrm{p}$ $<0.01)$, and with wellness $(r=0.47 ; p<0.01)$; and meaning in life with wellness $(r=0.46 ; p<0.01)$.

Table 1. Description Statistics for scaled variables

\begin{tabular}{|c|c|c|c|c|}
\hline & Mean & SD & Min & Max \\
\hline Stability & 91,33 & 7,33 & 63 & 110 \\
\hline Plasticity & 66,74 & 9,14 & 43 & 90 \\
\hline Wellness & 94,3 & 9,55 & 72 & 115 \\
\hline Meaning in Life & 18,28 & 2,68 & 10 & 24 \\
\hline
\end{tabular}

$\mathrm{N}=273$; SD: Standard Deviation

\subsection{Test of Measurement Model}

Test of measurement model showed that all variables were significantly correlated (see Table 2). The measurement model demonstrated satisfactory fit with the data: $\left[\chi^{2}(84, N=273)=224.69, p<0.001 ; G F I=0.90\right.$; IFI $=0.94 ;$ CFI $=0.94 ;$ SRMR $=0.062 ;$ RMSEA $=0.078$ $(90 \%$ CI for RMSEA $=0.066 ; .091)]$. All latent variables in the model were statistically significant and had tvalues ranging between 3.62 and 12.13 .

Table 2. Correlations in the measurement model

\begin{tabular}{|c|c|c|c|}
\hline Variables & Stability & Plasticity & MIL \\
\hline Stability & 1 & & \\
\hline Plasticity & 0.66 & 1 & \\
\hline MIL & 0.36 & 0.31 & 1 \\
\hline Wellness & 0.68 & 0.82 & 0.50 \\
\hline
\end{tabular}

$\mathrm{N}=273 ; \mathrm{p}<0.001 ;$ MIL: Meaning in Life 


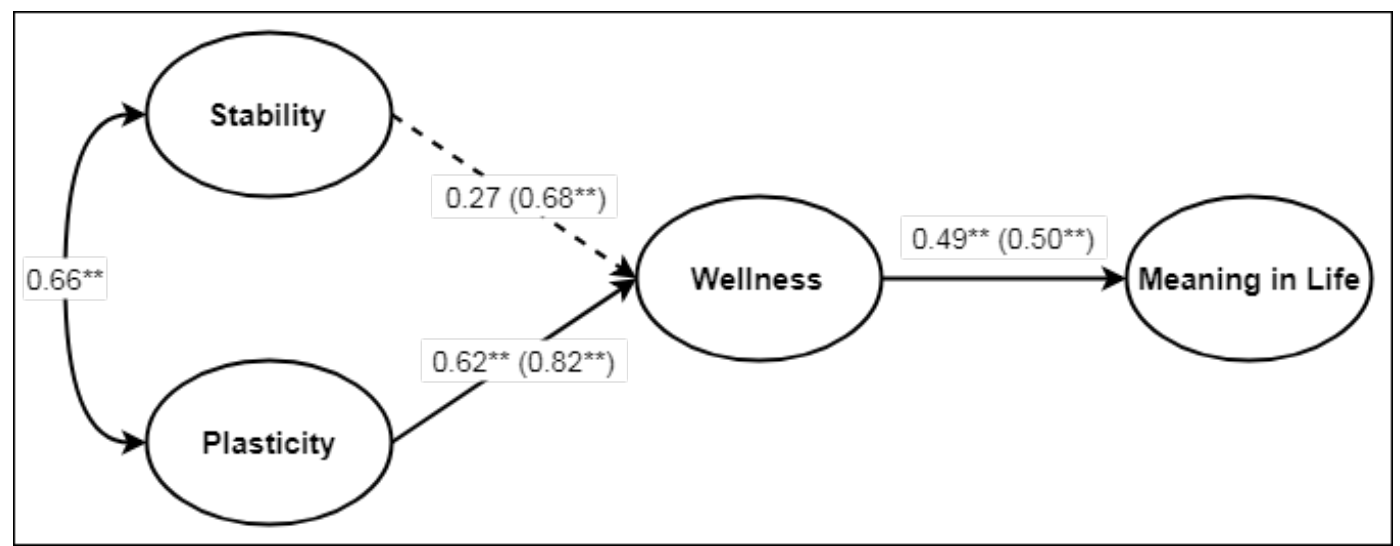

Figure 2. Standardized parameter estimates of the proposed model.

\subsection{Test of Structural Model}

The structural model involving stability and plasticity as independent variables; presence of meaning was dependent variable and the wellness as mediating variables was run. In the model $\mathrm{A}$, mediation of wellness in the relationship between plasticity/stability and presence of MIL was examined $\left[\chi^{2}(86, \mathrm{~N}=273)=\right.$ 226.67, $\mathrm{p}<0.001$; GFI $=0.90$; IFI $=0.94$; CFI $=0.94$; SRMR $=0.064$; RMSEA $=0.078(90 \%$ CI for RMSEA $=0.065 ; .090)]$. In this model the path from stability to wellness was not significant $(\beta=0.27 ; \mathrm{t}=1.99)$ thus this path was excluded from the model. The chi square differences showed that $\left(\Delta \chi^{2}(1)=0.11, p>n s\right)$ this model 2. This comparison showed that first model has better fit. Then new model (Model 3) involving a path from stability to presence was tested but chi square differences $\left(\Delta \chi^{2}(1)=0.22, \mathrm{p}>\mathrm{ns}\right)$ showed that first model has better fit. Finally, paths from plasticity to presence were added (Model 4). The chi square differences showed that $\left(\Delta \chi^{2}\right.$ (1) $=2.49, \mathrm{p}>\mathrm{ns}$ ) Model 1 had better fit. Also, in the Model 4 path from plasticity to meaning in life was not significant $(\beta=-0.28 ; t=-1.15)$. These results showed that (Model 1) wellness fully mediated the relationship between plasticity and presence (see Fig 2).

An alternative structural equation model was also tested to rule out the possibility that the fit of the proposed model was simply the result of a statistical coincidence. The alternative model proposed that stability and plasticity as independent variables; wellness was dependent variable and the meaning in life as mediating variables. The alternative model $\left[\chi^{2}(86, \mathrm{~N}=\right.$ $273)=320.72, \mathrm{p}<0.001 ; \mathrm{GFI}=0.86 ; \mathrm{IFI}=0.90 ; \mathrm{CFI}=$ $0.90 ;$ SRMR $=0.11$; $\mathrm{RMSEA}=0.10(90 \% \mathrm{CI}$ for RMSEA $=0.089 ; .011)]$ were worse than the proposed model also meaning in life did not mediate between stability/personality and wellness.

The relation between plasticity and meaning in life, we used PROCESS macro in SPSS (Hayes 2013; model 4) with meaning in life as the dependent variable plasticity as the independent variable, and the wellness as mediator.
The result showed that the path from plasticity to wellness $(\mathrm{b}=.488, \mathrm{SE}=.056, \mathrm{p}<.001)$ the paths from wellness to meaning in life $(\mathrm{b}=.186, \mathrm{SE}=.0275, \mathrm{p}<.001)$ were all significant. The direct path from plasticity to meaning became insignificant $(\mathrm{b}=.048, \mathrm{SE}=.0287, \mathrm{p}$ $=.093)$. The proposed model $(\mathrm{F}(2,270)=38,24 ; \mathrm{p}$ $<.001$ ) for this situation explains the $47 \%$ of the total variance.

\section{Discussion}

In conclusion, we can say that the stable personality trait including to the neuroticism, agreeableness and conscientiousness variables does not explain meaning in life. However, the plasticity trait does explain meaning in life. Moreover, the relationship between plasticity and meaning in life is mediated by wellness. In other words, the increase in the plasticity trait pertaining to extraversion and openness cause and increase in the level of individuals' understanding of meaning in life. The increase in one's wellness in this relationship is an important mediating variable. Additionally, we can say that both stability and plasticity explain wellness.

The first hypothesis of the study was examined by investigating the mediating role of wellness in the relationship between stability and meaning in life. Findings revealed that wellness was not found to be as a significant mediator. Stability consists of the neuroticism, agreeableness and conscientiousness factors. Upon examination, the researches $[1,2,33]$, showed that meaning in life was positively related to agreeableness and conscientiousness, but was negatively related to neuroticism. In a study conducted with university students, Lavigne et al. [34] found that only conscientiousness in the subdimensions of stability predicts meaning in life. In another study conducted with adults, one of the descriptors of meaning in life is only neuroticism in the dimensions of stability; the others do not explain the meaning [33] In this sense, we could hypothesize that the negative effect of neuroticism 
affected the other dimensions and that it may have caused the stability factor to not explain meaning in life. The results of this study show that the stable personality trait representing the socialization period as proven in previous research $[1,2,33]$ is associated with meaning in life, but it is not a predictive factor for each dimension.

In evaluating the second hypothesis of the study, wellness was found to be a significant mediator between plasticity and meaning in life. These results suggest support for the second hypothesis. Meaning in life explaining plasticity, which consists of extraversion and openness, corresponds to the research results that show that these structures are associated with each other $[1,2,33]$. It was found in previous research [33] that openness is the predictor of meaning in life. In another study, it was stated that meaning in life was explained through extraversion and conscientiousness [73]. As it can be seen different personality traits in the research results clarify the meaning in life. Another comprehensive study conducted with four different personality scales shows that the extraversion and openness traits are directly linked to meaning in life [31]. In the literature, the plasticity factor mostly represents concepts such as self-actualization and realizing one's full potential in humanistic approach. Similarly, the concept of meaning in life is a component based on existentialist philosophy and is part of a humanistic approach. On the other hand, both plasticity and well-being are closely related to ego-resilience. The reason of the relationship between these two concepts may be due to both plasticity and meaning in life essentially benefiting from the same approaches.

One of the findings obtained from this research directs to both stability and plasticity explaining wellness. McCrae and Costa [74] argue that personality affects wellbeing in many ways. At the same time Şimşek [75] has found that both stability and plasticity are predictors of subjective and psychological well-being. This situation, when considering the close relationship between wellness and wellbeing [76] corresponds to the results of this research. In a study that examines healthy behaviors, it was found that the personality traits of conscientiousness and agreeableness are reliable personality traits that explain healthy lifestyle [60]. The present study shows that wellness is a stronger predictor of plasticity compared to stability.

The fact that the relationship between these two structures is provided through wellness can be explained by the link between life satisfaction and meaning at a high-level and physical and mental wellbeing [73]. Having a meaning or a goal in life is directly linked to a healthy lifestyle [77]. For example, a study shows that adults find the times when they didn't smoke more meaningful than the times they did [78]. Examining the factors including plasticity, the traits of extroverted individuals such as being energetic, social, enthusiastic, and enterprising can be closely related to the social aspect of wellness, and this may have contributed to meaning in life. As for openness, it shows similarities to the cognitive dimension of wellness. A study conducted with elders' shows that emotional support is effective for re-forming meaning in life after stressful situations [79]. Through this lens, plastic individuals seem to need to have to social, physical, emotional, spiritual, cognitive wellness in order to have meaning in their lives.

\section{Conclusion and Suggestions}

Ultimately, it can be said that wellness mediates the relationship between plasticity and meaning in life. Accordingly, it can be argued that it is important to increase wellness in order to promote personal flexibility and enhanced understanding of the meaning of life. Therefore, studies enhancing wellness can be conducted.

On this subject, research can be done by approaching resources on meaning in life separately. Thus, in-depth information on the subject of personality and the sources of meaning in life can be reached. On the other hand, the research can be repeated with different age groups, especially with elders who are often studied in regard to wellness and meaning in life. However, how the personality traits of individuals who pull through serious health problems such injury or chronic illness have an impact on refining the meaning in their lives and the role that wellness undertakes in this regard can also be studied. Psychoeducation programs, the wellness-based ones in particular, are considered to be effective for individuals suffering from various diseases and traumas. In this context, we can also say that wellness-based programs would be more effective for individuals who display flexible personality traits in regard to finding meaning in their lives.

\section{REFERENCES}

[1] Steger, M. F., Frazier, P., Oishi, S., \& Kaler, M. (2006). The meaning in life questionnaire: Assessing the presence of and search for meaning in life. Journal of Counseling Psychology, 53(1), 80-93.

https://doi.org/10.1037/0022-0167.53.1.80

[2] Steger, M. F., Kashdan, T. B., Sullivan, B. A., \& Lorentz, D. (2008). Understanding the search for meaning in life: personality, cognitive style, and the dynamic between seeking and experiencing meaning. Journal of Personality, 76(2), 199-228.

https://doi.org/10.1111/j.1467-6494.2007.00484.x

[3] Krok, D., \& Telka, E. (2018). Meaning in life in cancer patients: relationships with illness perception and global meaning changes, Health Psychology Report, 3 (1)

[4] Czekierda, K., Gancarczyk, A., \& Luszczynska, A. (2014). 
Associations between meaning in life and health indicators: A systematic review. European Health Psychologist, 16 (S), 432.

[5] McMahon, S. \& Fleury, J. (2012) Wellness in older adults: A concept analysis, Nursing Forum, 47 (1), 39-51

[6] Edmonds, G.W. (2011). Personality and the healthy lifestyle as predictors of physical health: Can the healthy lifestyle be explained by personality? Unpublished PhD dissertation, University of Illinois at Urbana-Champaign Illinois, USA,

http://citeseerx.ist.psu.edu/viewdoc/download?doi=10.1.1 $.222 .9495 \&$ rep $=$ rep $1 \&$ type $=$ pdf

[7] Turiano, N. A., Pitzer, L., Armour, C., Karlamangla, A., Ryff, C. D., \& Mroczek, D. K. (2012). Personality trait level and change as predictors of health outcomes: Findings from a national study of Americans (MIDUS). The Journals of Gerontology Series B: Psychological Sciences and Social Sciences, 67(1), 4-12. http://doi.org/10.1093/geronb/gbr072

https://www.ncbi.nlm.nih.gov/pmc/articles/PMC3410684

[8] Terracciano, A., McCrae, R. R., \& Costa Jr, P. T. (2006). Longitudinal trajectories in Guilford-Zimmerman temperament survey data: Results from the Baltimore longitudinal study of aging. The Journals of Gerontology Series B: Psychological Sciences and Social Sciences, 61(2), P108-P116.

[9] Digman, J. M. (1997). Higher-order factors of the Big Five. Journal of personality and social psychology, 73(6), 1246.

[10] DeYoung, C. G. (2006). Higher-order factors of the Big Five in a multi-informant sample. Journal of personality and social psychology, 91(6), 1138.

[11] Saucier, G., Georgiades, S., Tsaousis, I., \& Goldberg, L. R. (2005). The factor structure of Greek personality adjectives. Journal of Personality and Social Psychology, 88(5), 856-875.

https://doi.org/10.1037/0022-3514.88.5.856

[12] Zhou, X., Saucier, G., Gao, D., \& Liu, J. (2009). The factor structure of Chinese personality terms. Journal of Personality, 77(2), 363-400. https://doi.org/10.1111/j.1467-6494.2008.00551.x

[13] Şimşek, Ö. F., Koydemir, S., \& Schütz, A. (2012). A multigroup multitrait-multimethod study in two countries supports the validity of a two-factor higher order model of personality. Journal of Research in Personality, 46(4), 442-449. https://doi.org/10.1016/j.jrp.2012.04.005

[14] DeYoung, C. G. (2015). Cybernetic Big Five Theory. Journal of Research in Personality, 56, 33-58. https://doi.org/10.1016/j.jrp.2014.07.004

[15] Chang, L., Connelly, B. S. \& Geeza, A. a. (2012). Separating method factors and higher order traits of the Big Five: a meta-analytic multitrait-multimethod approach. Journal of Personality and Social Psychology, 102(2), 408-426. doi:10.1037/a0025559

[16] DeYoung, C. G., Peterson, J. B., \& Higgins, D. M. (2002). Higher-order factors of the Big Five predict conformity: Are there neuroses of health? Personality and Individual Differences, 33(4), 533-552. https://doi.org/10.1016/S0191-8869(01)00171-4
[17] DeYoung, C. G. (2013). The neuromodulator of exploration: A unifying theory of the role of dopamine in personality. Frontiers in Human Neuroscience, 7, 762.

[18] Yamagata, S., Suzuki, A., Ando, J., Ono, Y., Kijima, N., Yoshimura, K., ... Jang, K. L. (2006). Is the genetic structure of human personality universal? A cross-cultural twin study from North America, Europe, and Asia. Journal of Personality and Social Psychology, 90(6), 987-98. https://doi.org/10.1037/0022-3514.90.6.987

[19] Steger, M. F. (2009). Meaning in Life. In S. J. Lopez (Ed.), Oxford handbook of positive psychology (2nd ed., pp. 679-687). Oxford: Oxford University Press.

[20] Steger, M. F. (2012). Experiencing Meaning in Life: Optimal Functioning at the Nexus of Well-Being, Psychopathology, and Spirituality. In The human quest for meaning: A handbook of psychological research and clinical applications (2nd ed., pp. 165-185). New York: Taylor \& Francis Group.

[21] Baumeister, R. F. (1991). Meanings of life. New York: Guilford

[22] Martela, F., \& Steger, M. F. (2016). The three meanings of meaning in life: Distinguishing coherence, purpose, and significance. Journal of Positive Psychology, 11(5), 531-545.

https://doi.org/10.1080/17439760.2015.1137623.

[23] Seligman M. E. P. \& Csikszentmihalyi M. (2000). Positive Psychology: An Introduction. American Psychologist 55/1 (2000) 5-14. Doi:10.1037//0003-066X.55.1.5

[24] Czekierda, K., Banik, A., Park, C. L., \& Luszczynska, A. (2017). Meaning in life and physical health: systematic review and meta-analysis. Health Psychology Review, 7199 (December), 1-32.

https://doi.org/10.1080/17437199.2017.1327325

[25] Demirbaş-Çelik, N. (2016). The relationship between meaning in life and the purpose of life for university students. Mediterranean Journal of Humanities, 6(1), 133-141. https://doi.org/10.13114/MJH.2016119294

[26] Ho, M. Y., Cheung, F. M., \& Cheung, S. F. (2010). The role of meaning in life and optimism in promoting well-being. Personality and individual differences, 48(5), 658-663.

[27] Steger, M. F., Oishi, S., \& Kesebir, S. (2011). Is a life without meaning satisfying? The moderating role of the search for meaning in satisfaction with life judgments. The Journal of Positive Psychology, 6(3), 173-180. https://doi.org/10.1080/17439760.2011.569171

[28] Ryff, C. D. (1995). Psychological well-being in adult life. Current directions in psychological science, 4(4), 99-104.

[29] Scannell, E. D., Allen, F. C., \& Burton, J. (2002). Meaning in life and positive and negative well-being. North American Journal of Psychology.

[30] Steger, M. F., Kashdan, T. B., Sullivan, B. a, \& Lorentz, D. (2008). Understanding the search for meaning in life: personality, cognitive style, and the dynamic between seeking and experiencing meaning. Journal of Personality, 76(2), 199-228. https://doi.org/10.1111/j.1467-6494.2007.00484.x 
[31] Schnell, T., \& Becker, P. (2006). Personality and meaning in life. Personality and Individual Differences, 41(1), 117-129. https://doi.org/10.1016/j.paid.2005.11.030

[32] Francis, L. J., \& Hills, P. R. (2008). The development of the Meaning in Life Index (MILI) and its relationship with personality and religious behaviours and beliefs among UK undergraduate students. Mental Health, Religion \& Culture, 11(2), 211-220.

https://doi.org/10.1080/13674670701243758

[33] Işık, Ş., \& Ü Zbe, N. (2015). Personality traits and positive/negative affects: An analysis of meaning in life among adults. Kuram ve Uygulamada Egitim Bilimleri, 15(3), 587-595.

https://doi.org/10.12738/estp.2015.3.2436

[34] Lavigne, K. M., Hofman, S., Ring, A. J., Ryder, A. G., \& Woodward, T. S. (2013). The personality of meaning in life: Associations between dimensions of life meaning and the Big Five. The Journal of Positive Psychology, 8(1), 34-43. https://doi.org/10.1080/17439760.2012.736527

[35] McMahon, S. \& Fleury, J. (2012) Wellness in older adults: A concept analysis, Nursing Forum, 47 (1), 39-51

[36] Corbin, C. B., Welk, G. J., Corbin, W. R. \& Welk, K. (2010). Concepts of fitness and wellness: A comprehensive lifestyle approach (9th ed.). St. Louis: McGraw-Hill Higher Education

[37] Myers, J. E., Sweeney, T. J., \& Witmer, J. M. (2000). The wheel of wellness counseling for wellness: A holistic model for treatment planning. Journal of Counseling and Development, 78(3), 251-266.

[38] Miller, G.D. ve Foster, L.T. (2010). Critical synthesis of wellness literature.

http://silvrnetwork.net/sites/silvrnetwork.org/files/library/ Critical_Synthesis\%2520of\%2520Wellness\%2520Update .pdf adresinden alınmıştır.

[39] Myers, J. E. \& Sweeney, T. J. (2004). The indivisible self: An evidence-based model of wellness. Journal of Individual Psychology, 60, 234-244.

[40] Korkut-Owen, F. ve Owen. D.W. (2012). İyilik Hali Yıldızı Modeli, uygulanması ve değerlendirilmesi. Uluslararası Avrasya Sosyal Bilimler Dergisi, 3(9), 24-33.

[41] Korkut-Owen, F., Doğan, T., Demirbaş Çelik, N. ve Owen, D. W. (2016). İyilik Hali Yıldızı Ölçeği’nin geliştirilmesi. Journal of Human Sciences, 13(3), 5013-5031. doi:10.14687/jhs.v13i3.4130

[42] Ryff, C. D. (1989). Happiness is everything, or is it? Explorations on the meaning of psychological well-being. Journal of personality and social psychology, 57(6), 1069.

[43] Battista, J., \& Almond, R. (1973). The development of meaning in life. Psychiatry, 36, 409-427. https://doi.org/10.1177/0040571X7908200403

[44] Debats, D. L., Drost, J., \& Hansen, P. (1995). Experiences of meaning in life: A combined qualitative and quantitative approach. British Journal of Psychology, 86(3), 359-375.

https://doi.org/10.1111/j.2044-8295.1995.tb02758.x

[45] Zika, S., \& Chamberlain, K. (1992). On the relation between meaning in life and psychological well-being.
British Journal of Psychology, 83(1), 133-145.

[46] Fry, P. S. (2000). Religious involvement, spirituality and personal meaning for life: Existential predictors of psychological wellbeing in community-residing and institutional care elders. Aging \& Mental Health, 4(4), 375-387.

[47] Mascaro, N., \& Rosen, D. H. (2006). The role of existential meaning as a buffer against stress. Journal of Humanistic Psychology, 46(2), 168-190.

[48] Pan, J. Y., Wong, D. F. K., Chan, C. L. W., \& Joubert, L. (2008). Meaning of life as a protective factor of positive affect in acculturation: A resilience framework and a cross-cultural comparison. International Journal of Intercultural Relations, 32(6), 505-514.

[49] Martela, F., Ryan, R. M., \& Steger, M. F. (2017). Competence, relatedness, and beneficence: Comparing the four satisfactions and positive affect as predictors of meaning in life. Journal of Happiness Studies. 1-22. https://doi.org/10.1007/s10902-017-9869-7

[50] King, L. A., Hicks, J. A., Krull, J. L., \& Del Gaiso, A. K. (2006). Positive affect and the experience of meaning in life. Journal of Personality and Social Psychology, 90(1), 179-196. https://doi.org/10.1037/0022-3514.90.1.179

[51] Weinstein, N., Ryan, R. M., \& Deci, E. L. (2012). Motivation, meaning and wellness: A self-determination perspective on the creation and internalization of personal meanings and life goals. In P. T. P. Wong (Ed.), The human quest for meaning: Theories, research, and applications (pp. 81-106). New York: Taylor \& Francis Group.

[52] Wong, P. T. (1989). Personal meaning and successful aging. Canadian Psychology/Psychologie Canadienne, 30(3), 516-525. https://doi.org/10.1037/h0079829

[53] Park, C. L., Malone, M. R., Suresh, D. P., Bliss, D., \& Rosen, R. I. (2008). Coping, meaning in life, and quality of life in congestive heart failure patients. Quality of Life Research, 17(1), 21-26. https://doi.org/10.1007/s11136-007-9279-0

[54] Heisel, M. J., Neufeld, E., \& Flett, G. L. (2016). Reasons for living, meaning in life, and suicide ideation: Investigating the roles of key positive psychological factors in reducing suicide risk in community-residing older adults. Aging and Mental Health, 20(2), 195-207. https://doi.org/10.1080/13607863.2015.1078279

[55] Pirtle, T., Wang, X., Brown, R., \& Lainas, H. L. (2017). Influence of a wellness course on meaning-in-life and anxiety of counselors-in-training. Journal of Hispanic Higher Education, 153819271771913. https://doi.org/10.1177/1538192717719131

[56] Britzman, M. J., \& Henkin, A. L. (1992). Wellness and personality priorities: The utilization of Adlerian encouragement strategies. Individual Psychology: Journal of Adlerian Theory, Research \& Practice, 48(2), 194-202.

[57] Schmutte, P. S., \& Ryff, C. D. (1997). Personality and well-being: Reexamining methods and meanings. Journal of Personality and Social Psychology, 73(3), 549-559.

[58] Conway, T.L.; Vickers Jr., R.R.; Wallston, K.A. \& Costa Jr., P.T. (1992) Personality, health locus of control and 
health behavior. Paper presented at 1992 Annual Convention of the American Psychological Association, Washington D.C. August 14-18 1992.

[59] Marzuki, N.A., \& Ishak, A.K. (2011). Towards healthy organization in correctional setting: Correctional officers' wellness, occupational stress and personality, International Journal of Social Sciences and Humanity Studies, 3(2), 355-365.

[60] Booth-Kewley, S., \& Vickers, R.R. (1994). Associations between major domains of personality and health behaviour. Journal of Personality, 62, 281-298. DOI: 10.1111/j.1467-6494.1994.tb00298.x

[61] Cloninger, C. R. \& Zohar, A.H. (2011). Personality and the perception of health and happiness. Journal of Affective Disorders, 128, 24- 32.

[62] Larson, J. S. (1999). The conceptualization of health. Medical Care Research and Review, 56, 123-136.

[63] Steger, M.F., and Kashdan, T. B. (2007). Stability and specificity of meaning in life and life satisfaction over one year, Journal of Happiness Studies, 8:161-179, DOI: 10.1007/s10902-006-9011-8.

[64] Costa, P. T., \& Mccrae, R. R. (1994). 2B - Set like plaster Evidence for the stability of adult personality. In T. F. Heatherton \& J. L. Weinberger (Eds.), Can personality change? (pp. 21-40). Washington, DC: American Psychological Association.

[65] John, O. P., \& Srivastava, S. (1999). The Big Five trait taxonomy: History, measurement, and theoretical perspectives. Handbook of personality: Theory and research, 2(1999), 102-138.

[66] Sümer, N., Lajunen, T., \& Özkan, T. (2005). Big five personality traits as the distal predictors of road accident involvement. In G. Underwood (Ed.), Traffic and transport psychology: Theory and application (pp. 215-227). Elsevier.

[67] Korkut-Owen, F., Demirbaş-Çelik, N., \& Doğan, T. (2017). Yetişkinlerde iyilik hali. Uluslararası Sosyal Araştırmalar Dergisi, 10(53), 600-611.

[68] Demirbaş N. (2010). Yaşamda anlam ve yılmazlık. Yayımlanmamış yüksek lisans tezi. Hacettepe Üniversitesi, Ankara.

[69] Terzi, Ş., Erguner-Tekinalp, B., \& Leuwerke, V. (2011). Yaşamdaki Anlam Ölçeğinin çeşitli yaş gruplarına göre psikometrik özelliklerinin değerlendirilmesi. In XI.
National Congress of Counseling and Guidance. İzmir.

[70] Anderson, J. C., \&Gerbing, D. W. (1988). Structural equation modeling in practice: a review of recommended two step approaches. Psychological Bulletin, 103, 411-423.

[71] Weston, R., \& Gore, P. A., Jr. (2006). A brief guide to structural equation modeling. The Counseling Psychologist, 34, 719-751. doi:10.1177/0011000006286345

[72] Preacher, K. J., \& Hayes, A. F. (2008). Asymptotic and resampling strategies for assessing and comparing indirect effects in multiple mediator models. Behavior research methods, 40(3), 879-891.

[73] Eakman, A. M., \& Eklund, M. (2012). The relative impact of personality traits, meaningful occupation and occupational value on meaning in life and life satisfaction. Journal of Occupational Science, 19(2), 165-177. https://doi.org/10.1080/14427591.2012.671762

[74] McCrae, R. R., \& Costa, P. T. (1991). The NEO Personality Inventory: Using the Five-Factor ModeI in counseling. Journal of Counseling \& Development, 69(4), 367-372.

https://doi.org/10.1002/j.1556-6676.1991.tb01524.x

[75] Simşek, O. F. (2014). Higher order structure of personality and mental health: does general affectivity matter? Journal of Personality Assessment, 96(2), 226-36. https://doi.org/10.1080/00223891.2013.836527

[76] Hermon, D. A., \& Hazler, R. J. (1999). Adherence to a wellness model and perceptions of psychological well being. Journal of Counseling \& Development, 77(3), 339-343

[77] Roepke, A. M., Jayawickreme, E., \& Riffle, O. M. (2013). Meaning and Health: A Systematic Review. Applied Research in Quality of Life, 9(4), 1055-1079. https://doi.org/10.1007/s11482-013-9288-9

[78] Thege, B. K., Bachner, Y. G., Martos, T., Kushnir, T., \& Konkoly Thege, B. (2009). Meaning in life: Does it play a role in smoking. Substance Use \& Misuse, 44(11), 1566. https://doi.org/10.1080/10826080802495096

[79] Krause, N. (2004). Stressors arising in highly valued roles, meaning in life, and the physical health status of older adults. The Journals of Gerontology. Series B, Psychological Sciences and Social Sciences, 59(5), S287-97. https://doi.org/59/5/S287 